\title{
Antennas and Photovoltaic Panels: Toward a Green Internet of Things
}

\author{
R. Caso, R. Garroppo, S. Giordano, G. Manara, \\ A. Michel, P. Nepa, L. Tavanti \\ Dept. Information Eng., University of Pisa, Pisa, Italy \\ r.caso[r.garroppo, s.giordano, g.manara,, a.michel, p.nepa, \\ l.tavanti]@iet.unipi.it
}

\author{
M. Magnarosa, G. Nenna \\ CUBIT s.c.a.r.l. \\ Navacchio, Pisa, Italy \\ marco.magnarosa[guido.nenna]@cubitlab.com
}

\begin{abstract}
The perspective of a wide use of green power motivates the scientific community to study the possibility of fabricating integrated stand-alone devices. In particular, solar energy is one of the most promising renewable powers, and it is widely used in autonomous wireless communication systems. Specifically, integration of sensors and antennas in a solar panel represents a challenge for future technology. In this paper, the feasibility of a single integrated autonomous device equipped with WiFi capability is analyzed, discussing its potentiality in the framework of the Internet of Things.
\end{abstract}

Index Terms - Integration, slot antennas, PV panel, solar cells, stand-alone systems, Wireless Sensor Networks.

\section{INTRODUCTION}

The increasing demand of energy and the growing sensitivity to environmental issues are leading research to study and improve the renewable energy sources as well as optimizing the energy consumption [1]. In particular, photovoltaic (PV) energy is widely used in autonomous communication system due to its eco-friendliness and reliability. In 2009 it was estimated that at the end of this century the solar power generation will account for more than $60 \%$ of world's totally [2].

To date, solar panels are used in some stand-alone wireless communication systems, especially in isolated environments. However, PV panel, sensors and antenna are separate elements of the same system, causing relatively great space employment, engineering and design problems. Therefore a compromise in the utilization of the limited available space is needed and sensor and antennas integration in PV panel is desirable.

In the last decades, antennas have been integrated in solar cells and photovoltaic panels. Most common technologies of PV panels integrated radiating elements are the innovative transparent [3]-[5], patch [6],[13] slot [14],[18] and inverted-F [19] antennas.

Several researchers are interested in innovative transparent antenna, made by TCOs (Transparent Conductor Oxides) [3][5]. These antennas may represent a good integrated solution because they are easily integrable on after-market solar cell. Nevertheless these TCOs are relatively expensive and with the existing technological capabilities is not easy to obtain a $90 \%$ sunlight transparency, needed for the proper functioning of the solar cell [4]. Solar cells may be used as a radiating patch [6] or as a coupled patch [7]-[9]. In these cases the cell dimensions are strictly related to the operating frequency, restricting the possible applications. Solar cells may be used also as a ground plane for an upper patch element [10]-[13], but with a reduction of the PV solar efficiency. Slot antennas may be realized between solar cells [14]-[17] or obtained by properly etching of them [18], but affecting the solar efficiency. Nevertheless, for high frequency applications the antenna PV panel integration is simpler.

Small photovoltaic panels are used also in consumer products such as battery recharger, access points or other personal devices (Fig. 1).

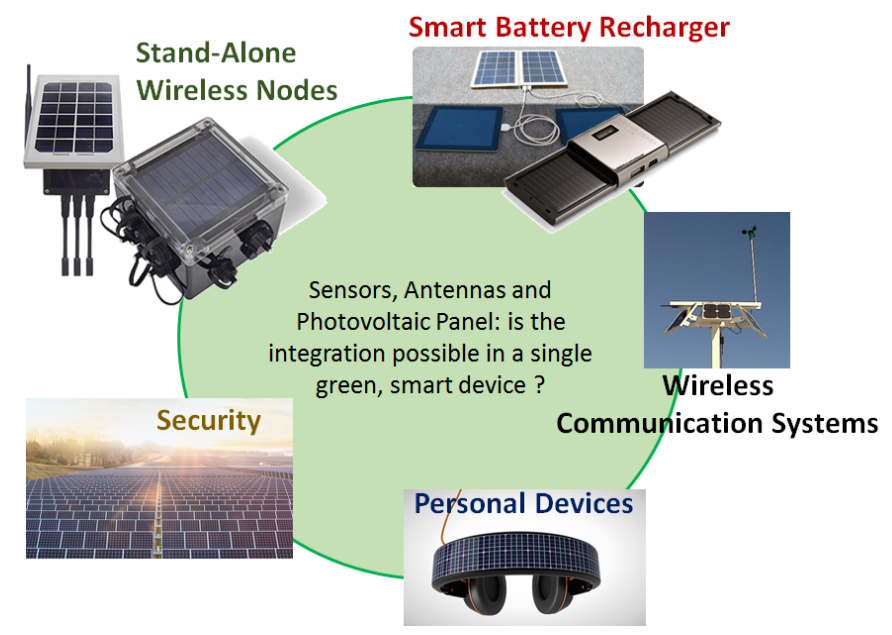

Fig. 1 Examples of applications in which sensors, antennas and photovoltaic panels could be integrated in a unique device.

In some of these systems, sensors are used to get information on humidity, temperature, geographical position, etc. It is clear that all the information can be transmitted to a base station and collected to remote monitor both the single devices and the overall network.

In this paper, the integration of sensor and antennas in photovoltaic panels is investigated, highlighting the potentiality of a Wireless Sensor Network composed by autonomous nodes equipped with integrated sensors and antennas. As a proof-ofconcept, a panel-to-panel link has been analyzed to assess the 
feasibility of a wireless sensor network composed by standalone nodes. To improve the link quality, smart PV panels can be equipped with more than one antenna. Indeed, exploiting the available space between the solar cells, a planar array can be obtained, providing the PV panel with beamforming capabilities.

\section{RECEIVED SIGNAL POWER AND GOODPUT MEASUREMENTS}

The main idea of the PV panel antenna integration is the exploitation of the available space among adjacent solar cells where only a cover glass layer is present above the antenna, without affecting the module solar efficiency.

A typical commercial PV panel has been considered for the antenna design. It is composed by 36 156-mm-side monocrystalline silicon $(\mathrm{m}-\mathrm{Si})$ square solar cells, which are incorporated between two ethylene vinyl acetate (EVA) layers. The cells plane is covered on the top and bottom side by two glass layers, for an overall thickness of about $8 \mathrm{~mm}$. The solar cells are separated from a distance of $25 \mathrm{~mm}$ each other. In Fig. $2 \mathrm{a}$, a potential position of a slot antenna among square solar cells is shown (dark color). The top view of the proposed antenna is also shown in Fig. 2b. This antenna is characterized by low cost materials and easy-integration in a PV panel (Fig. 2c), in order to obtain a cost limitation of the manufacturing process. The radiating element has been presented in [16] for GSM/UMTS (1710-2170 MHz) applications and optimized for IEEE $802.11 \mathrm{~b} / \mathrm{g}$ WLANs $(2400-2485 \mathrm{MHz})$ applications in [17]. The geometrical parameters of the final design are listed in Table I.
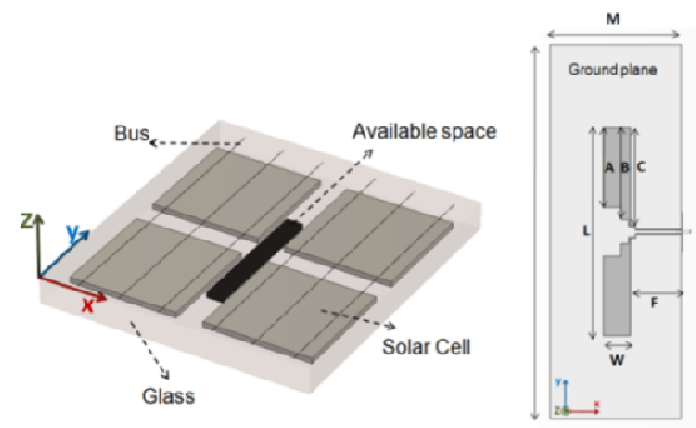

(a)

(b)

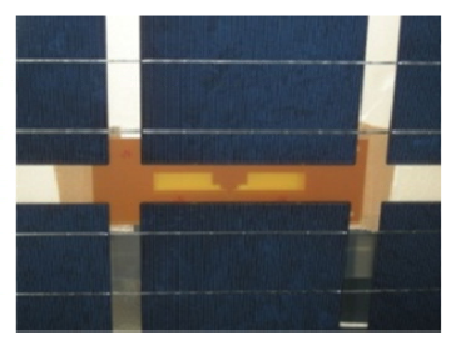

(c)
Fig. 2 The antenna presented in [14] has been here optimized for WiFi applications: (a) potential position of a slot antenna among square solar cells (b) top view of the proposed antenna and (c) antenna prototype integrated in a commercial PV panel.

\begin{tabular}{cccc}
\multicolumn{4}{c}{ TABLE I } \\
\hline \hline \multicolumn{4}{c}{ ANTENNA DIMENSIONS } \\
\hline \hline $\mathbf{N}$ & 200 & $\mathbf{A}$ & 27.6 \\
$\mathbf{M}$ & 45 & $\mathbf{B}$ & 28.8 \\
$\mathbf{L}$ & 67.5 & $\mathbf{C}$ & 30.3 \\
$\mathbf{W}$ & 5.6 & $\mathbf{F}$ & 18.3 \\
\hline \hline
\end{tabular}

The WiFi system performance has been investigated by measurements in the $2.4 \mathrm{GHz}$ ISM band. In the test (Fig. 3), two antennas were integrated in two different PV panel and used both as transmitting and receiving antennas. The antennas were connected to laptops through the TL-WN722N modules [20] and fed by $20 \mathrm{dBm}$ input power. The system performance was measured as a function of the distance (D) between the transmitter and receiver antennas, which are placed in line-ofsight and correctly aligned and polarized.

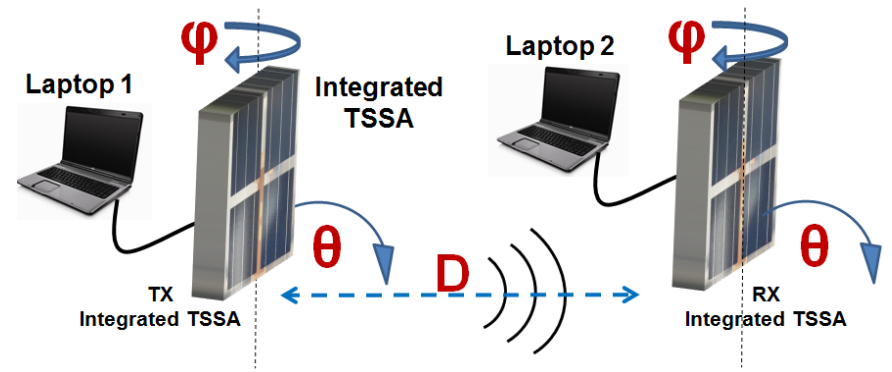

Fig. 3 Test setups: (a) the antenna and the commercial dipole performance comparison and (b) the panel-to-panel link analysis.

The panel-to panel link performance was measured in two modules relative position $\left(\varphi=0^{\circ}\right.$ and $\left.\varphi=90^{\circ}\right)$. A greater received signal power level (Fig. 4a) for the lateral communication $\left(\theta=0^{\circ}, \quad \varphi=90^{\circ}\right)$ was obtained respect to the frontal communication $\left(\theta=0^{\circ}, \varphi^{\circ} 0^{\circ}\right)$. A significant goodput reduction was observed by varying the distance D (Fig. 4b), as expected. However, a goodput greater than $5 \mathrm{Mbytes} / \mathrm{s}$ was obtained until $150 \mathrm{~m}$, that represented an acceptable value for most of the common wireless applications.

\section{PRELIMINARY RESUltS ON THE INTEGRATED ARRAY}

The measured performance on the WiFi integrated antenna demonstrated that a single, integrated, photovoltaic panel can be fabricated and used as an autonomous node of a Wireless Sensor Network. However, a specific attention has to be paid on the photovoltaic panel orientation. It is clear that the solar cells must be oriented toward the sun in order to maximize the power generation. On the other hand, two communicating network nodes can be arbitrarily positioned in the open space.

For these reasons, a number of antennas could be integrated in the same PV panel, and opportunely fed in order to orient the maximum radiation direction toward a specific direction where 
other network nodes are supposed to be. That is, the PV panel integrated array provides the smart panel with beamforming capabilities.

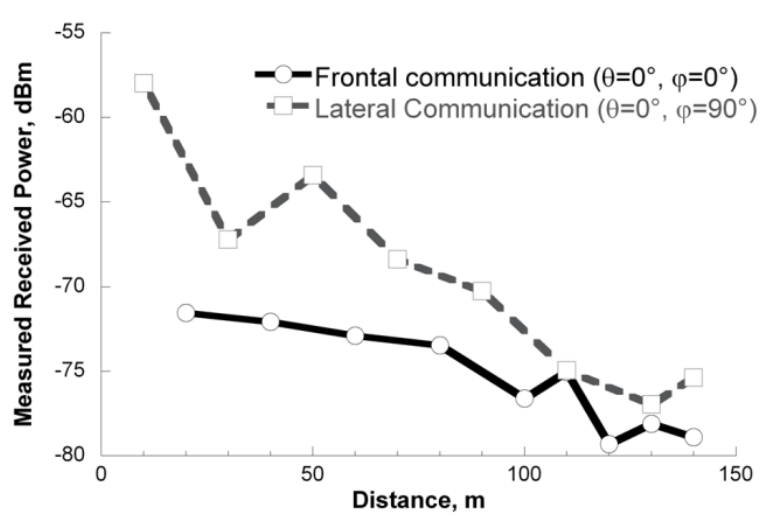

(a)

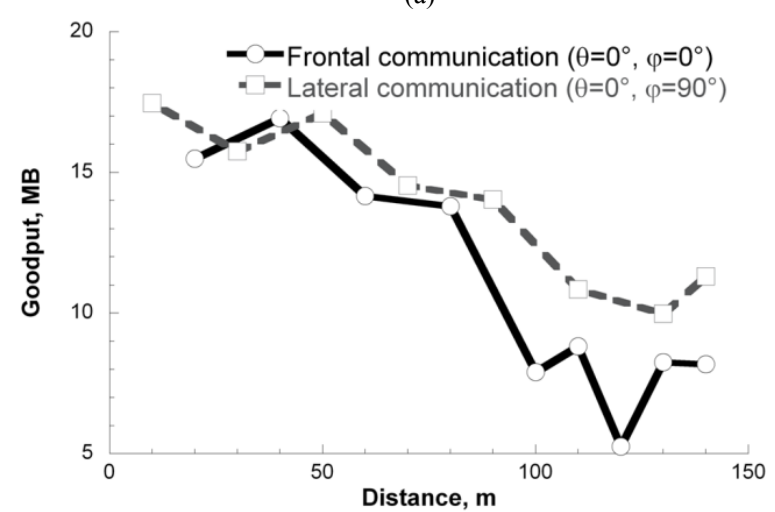

(b)

Fig. 4 Panel-to-panel link performance in terms of (a) received power level and (b) goodput.

To prove the feasibility of a PV panel integrated array, numerical simulations have been performed by using CST Microwave Studio $^{\circledR}$. As shown in Fig. 5, three WiFi antennas have been placed between the cells of a $4 \times 9$ solar cells PV panels.

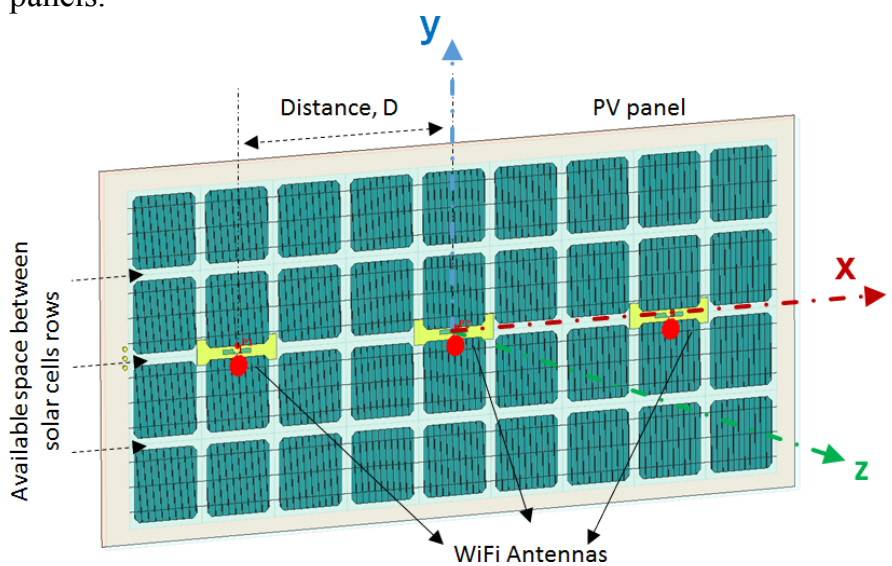

Fig. 5 Three WiFi antennas have been integrated in a photovoltaic panel to obtain a $3 \times 1$ array.

The maximum gain direction can be oriented by choosing a proper input phase of each radiating element. Let us consider an $M \times N$ planar array arranged on the XY plane as in Fig. 5. As usual, $\theta$ is the angle between the $z$-axis and the $x$-axis, while $\phi$ is the angle between the $x$-axis and the $y$-axis. In general, the current phase of the $(m, n)^{\text {th }}$ radiating element $\left(\alpha_{m n}\right)$ has to be set to

$$
\alpha_{m n}=-\beta\left(x_{m n} \sin \theta_{0} \cos \phi_{0}+y_{m n} \sin \theta_{0} \sin \phi_{0}\right)
$$

- where

- $\beta$ is the wavenumber in free space, and it is directly proportional to the operating frequency;

- $\left(x_{m n}, y_{m n}\right)$ represents the position of the $(m, n)^{\text {th }}$ element in the XY plane;

- $\left(\theta_{0}, \phi_{0}\right)$ represents the direction where the gain has to be maximized.

The distance $\mathrm{D}$ between two adjacent radiating elements plays an important role in the array radiative performance. In particular, the higher the distance between the antennas (but lower than $\lambda$ which represents the free-space wavelength), the higher is the gain. However, the distance D is also strictly related to the radiation pattern characteristics in case of beamforming (for example, for large distances D the grating lobes phenomenon could appear). Nevertheless, the distance between the radiating elements is highly affected by the presence of the radiating cells. Indeed, the available space between solar cells rows is limited and the distance between two free slots is set by the cell size. Anyway, the distance D can be chosen as a trade-off between the required array radiative performance and the physical limitations due to the presence of the solar cells.

To better assess the feasibility of an integrated antenna array, the three antennas shown in Fig. 5 have been properly fed to maximize the radiation toward a specific direction. In Fig. 6 the normalized radiation patterns of the $3 \times 1$ array of PV panel integrated antennas for WiFi applications are shown for the XZ plane (Fig. 5). In particular, the main lobe direction has been oriented to $\theta=0^{\circ}, \theta=10^{\circ}$ and $\theta=30^{\circ}$. When the main lobe is tilted toward $\theta=30^{\circ}$, the side lobe level is not negligible, and it could be not satisfactory for communication systems. Increasing the number of antennas and reducing the distance among them could allow for a lower side lobe level; however, also the number of radiating elements depends on the photovoltaic panel size. 


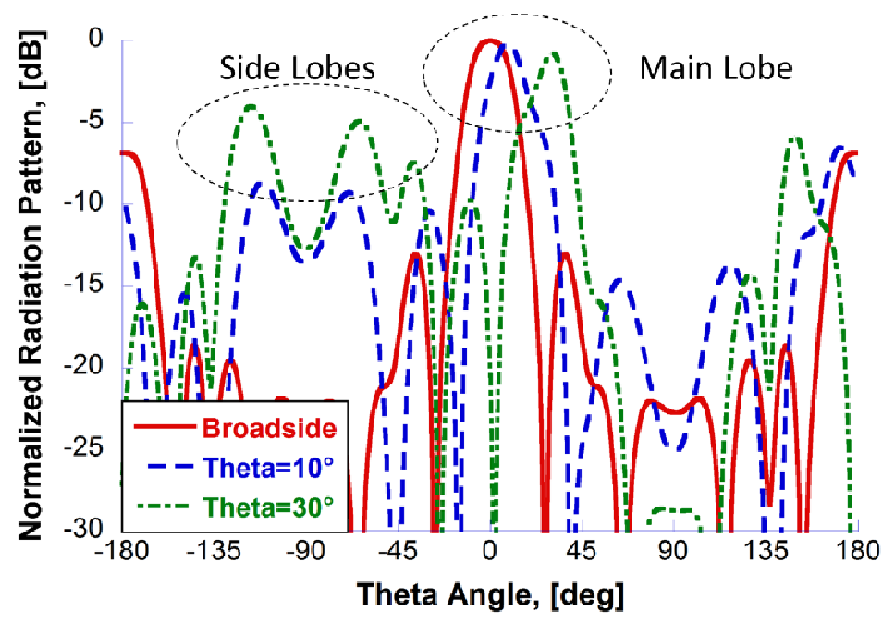

Fig. 6 Normalized radiation pattern of the $3 \times 1$ array of PV panel integrated antennas for WiFi applications.

\section{CONCLUSION}

Solar panels allow communication systems to be standalone, without the need of wired-feeding networks. That is, they can be installed and used in wild and rural environments. Arranging small devices equipped with green power sources (e.g. PV panels or windmill blade) in outdoor scenarios could represent a valuable solution for remote control and management of isolated areas. Moreover, Wireless Sensor Networks can be constructed (i.e. mesh networks) to collect and share data. Integrated sensors and antennas in the same autonomous device represent a challenge for the future Internet of Things. In this paper, the feasibility of an array of antennas integrated in a single photovoltaic panel has been investigated. Preliminary numerical results have been also presented, confirming that beamforming techniques can be implemented to orient the integrated array maximum gain direction toward a wireless network node, improving the overall network performance.

\section{REFERENCES}

[1] J. Serra, D. Pubill, A. Antonopoulos, and C. Verikoukis, "Smart HVAC control in IoT: energy consumption minimization with user comfort constraints", The Scientific World Journal, vol. 2014, Article ID 161874, 2104

[2] H. Yan, Z. Zhou, and H. Lu, "Photovoltaic industry and market investigation," International Conference on Sustainable Power Generation and Supply, ( SUPERGEN '09), pp.1,4, 6-7 April 2009

[3] M.J. Roo Ons, S.V. Shynu, M.J. Ammann, S.J. McCormack, and B. Norton, "Transparent patch antenna on a-Si thin-film glass solar module," Electronics Letters, vol.47, no.2, pp.85-86, Jan 2011.
[4] T. Yasin, and R. Baktur, "Inkjet printed patch antennas on transparent substrates," IEEE Antennas and Propagation Society International Symposium, 2010.

[5] T. Peter, T. A. Rahman, S. W. Cheung, R. Nilavalan, H. F. Abutarboush, and A. Vilches, "A Novel Transparent UWB Antenna for Photovoltaic Solar Panel Integration and RF Energy Harvesting", IEEE Transactions on Antennas and Propagation, vol. 62, no. 4, pp. 1844-1853, Apr 2014.

[6] T.W. Turpin, and R. Baktur, "Meshed Patch Antennas Integrated on Solar Cells," IEEE Antennas and Wireless Propagation Letters, vol. 8, pp. 693-696, 2009.

[7] N. Henze, A. Giere, H. Friichting, and P. Hofmann, "GPS Patch Antenna with Photovoltaic Solar Cells for Vehicular Applications," 58th IEEE Vehicular Technology Conference Fall, Orlando, US, Oct. 6-9, 2003.

[8] C. Bendel, J. Kirchhof, and N. Henze, "Application of photovoltaic solar cells in planar antenna structures," Proceedings of 3rd World Conference on Photovoltaic Energy Conversion, vol. 1, pp. 220 - 223, May 11-18, 2003.

[9] N. Henze, M. Weitz, P. Hofmann, C. Bendel, J. Kirchhof, and H. Fruchting, "Investigation of planar antennas with photovoltaic solar cells for mobile communications," 15th IEEE International Symposium on Personal, Indoor and Mobile Radio Communications, vol. 1, pp. 622 626, Sep. 5-8, 2004.

[10] S. Vaccaro, P. Torres, J.R. Mosig, et al., "Integrated solar panel antennas," Electronics Letters, 36, (5), pp. 390-391, 2000.

[11] M.J. Roo Ons, S.-V. Shynu, M.J. Ammann, S. McCormack, and B. Norton, "Investigation on Proximity-Coupled Microstrip Integrated PV Antenna," 2nd European Conference on Antennas and Propagation, Nov. 11-16, 2007.

[12] S.V. Shynu, M.J. Ammann, and B. Norton, "Quarter-wave metal plate solar antenna," Electronics Letters, vol. 44(9), pp. 570-571, Apr 2008

[13] S.V. Shynu, M.J. Roo Ons, P. McEvoy, M.J. Ammann, S.J. McCormack, and B. Norton, "Integration of Microstrip Patch Antenna With Polycrystalline Silicon Solar Cell," IEEE Transactions on Antennas and Propagation, vol. 57(12), pp. 3969-3972, Dec. 2009.

[14] M. Danesh, and J.R. Long, "Compact Solar cell Ultra-Wideband dipole antenna," IEEE Antennas and Propagation Society International Symposium, 2010.

[15] T. Wu, R.L. Li, and M.M. Tentzeris, "A mechanically stable, low profile, omni-directional solar cell integrated antenna for outdoor wireless sensor nodes," IEEE Antennas and Propagation Society International Symposium, 2009.

[16] Caso, R.; D'Alessandro, A.; Michel, A.; Nepa, P., "Integration of Slot Antennas in Commercial Photovoltaic Panels for Stand-Alone Communication Systems," IEEE Transactions on Antennas and Propagation, vol.61, no.1, pp.62,69, Jan. 2013

[17] Michel, A.; Caso, R.; Tavanti, L.; Gazzarrini, L.; Garroppo, R.; Nepa, P., "Design and performance analysis of a slot antenna integrated in a photovoltaic panel," IEEE Antennas and Propagation Society International Symposium (APSURSI), pp.1,2, 8-14 July 2012

[18] S.V. Shynu, M.J. Roo Ons, M.J. Ammann, B. Norton, and S. McCormack, "Dual band a-Si:H solar-slot antenna for $2.4 / 5.2 \mathrm{GHz}$ WLAN applications," 3rd European Conference on Antennas and Propagation, pp. 408-410, Mar. 23-27, 2009.

[19] O. O'Conchubhair, A. Narbudowicz, P. McEvoy, and M. J. Ammann, "Circularly Polarised Solar Antenna for Airborne Communication Nodes", Electronic Letters, vol. 51, no. 9, pp. 667-669, Apr. 2015

[20] http://www.tp-link.com/en/support/download/?model=TL-WN722N 